\title{
Evolução da consciência desenvolvimentista: da Cepal à Escola de Campinas
}

\author{
Developmentalist consciousness evolution: \\ from Eclac to Campinas' School
}

\section{Fábio Pádua dos Santos}

fpadua@gmail.com

Universidade Federal de Santa Catarina

\begin{abstract}
Resumo: A ascensão dos países latino-americanos nas hierarquias mundiais da riqueza e do poder no interior do sistema internacional é preocupação perene no pensamento desenvolvimentista. No presente artigo, apresentem-se, de modo didático e objetivo, as condições teóricas de superação do subdesenvolvimento tanto para o pensamento originário da CEPAL como para a Escola de Campinas. Argumenta-se que a essência da problemática da superação do subdesenvolvimento formulada pela CEPAL na década de 1950 continua presente na Escola de Campinas, muito embora, esta última reconheça que a dinâmica do capitalismo contemporâneo ampliou os constrangimentos à redução da brecha existente entre países subdesenvolvidos e desenvolvidos. Para tanto, são apresentadas as semelhanças e diferenças entre os esquemas analíticos da CEPAL e da Escola de Campinas com relação à noção de sistema capitalista, aos determinantes da relação centro-periferia e às possibilidades de superação do subdesenvolvimento. Como conclusão, sugere-se que a Escola de Campinas propôs uma revisão crítica dos fundamentos teóricos do estruturalismo latino-americano de modo a fundamentar e instrumentalizar a luta política pela redemocratização com vistas à inserção nacional soberana no sistema mundial capitalista financeirizado.
\end{abstract}

Palavras-chave: Capitalismo; Subdesenvolvimento; Relação Centro-Periferia; CEPAL; Escola de Campinas

Abstract: The rise of Latin American countries in the world hierarchies of wealth and power in the international system has been an enduring concern in the developmentalism thought. This paper presents, in a didactic and objective way, the theoretical conditions to overcome underdevelopment situations in both ECLAC early thought as well as for Campinas' School. The present paper argues the subject matter to overcome the underdevelopment formulated by ECLAC in the 1950s is still alive in the Campinas' School, although this school of thought recognizes that the dynamic of contemporary capitalism extended the constrains to reduce the gap between underdeveloped and developed countries. Therefore, in what follows, it will present the similarities and differences between both analytical frameworks ECLAC and Campinas' School in relation to the notion of capitalism system, the determinants of coreperiphery relation, and the possibilities to overcome the underdevelopment. By way of conclusion, it suggests Campinas' School has proposed a critical review of theoretical foundations of Latin American structuralism in order to ground and to instrumentalize the political struggle for redemocratization with a view to sovereign national insertion into the financialized capitalist world system.

Keywords: Capitalism; Underdevelopment; Core-Periphery Relation; ECLAC; Campinas' School

Recebido em: 26-10-2017. Aceito em: 15-12-2017.

Rev. Text. Econ., Florianópolis, v. 20 n. 2, p. 119 - 135, ago/dez. 2017 ISSN 2175-8085 


\section{INTRODUÇÃO}

A problemática do desenvolvimento nacional é a da superação do subdesenvolvimento. Conforme Celso Furtado, em Teoria e Política do Desenvolvimento Econômico, “[...] o subdesenvolvimento não constitui uma etapa necessária do processo de formação das economias capitalistas modernas. É, em si, uma situação particular, resultante da penetração de empresas capitalistas modernas em estruturas arcaicas." (FURTADO, 1967, p. 167). Historicamente, a luta pela superação do subdesenvolvimento tem consistido em transformar deliberadamente sistemas econômicos nacionais especializados e heterogêneos em direção a uma maior capacidade autônoma de crescimento, direcionando-os para as necessidades das respectivas sociedades que conformam unidades políticas nacionais. (SUNKEL; PAZ, 1970, p. 37). Deste prisma, tais transformações devem ser conduzidas pelo Estado a partir de reformas estruturais sumarizadas em projetos nacionais de desenvolvimento. Como bem exprime Furtado,

[...] essas reformas transcendem o quadro do que convencionalmente se chama de política econômica, pois constituem o coroamento de uma fase de agudas tensões sociais. As reformas surgem não como uma opção racional, e sim como abandono de certas posições pelos grupos que controlam o sistema de poder, ou como uma modificação da relação de forças dos grupos que disputam o controle do sistema de poder. (FURTADO, 1967, p. 207)

No presente artigo, apresentem-se, de maneira sistematizada, as condições de superação da situação de subdesenvolvimento ao pensamento desenvolvimentista, tanto para o pensamento originário da CEPAL como para a Escola de Campinas. Dito de outro modo, o artigo busca organizar, de modo didático e objetivo, as percepções de ambas as escolas de pensamento sobre a possibilidade de ascensão dos países latino-americanos nas hierarquias mundiais da riqueza e do poder no interior do sistema mundial moderno.

Nessa modesta incursão pelo tema, destaca-se que a essência da problemática da superação do subdesenvolvimento formulada pelo pensamento originário da CEPAL na década de 1950, continua válida para o pensamento desenvolvimentista consubstanciado atualmente na Escola de Campinas. Não obstante, esta última reconheça que a dinâmica do capitalismo contemporâneo ampliou os constrangimentos à redução da brecha entre os países periféricos e o mundo desenvolvido.

Argumenta-se que o reconhecimento das maiores dificuldades à superação do subdesenvolvimento foi possível em função da redefinição da problemática do desenvolvimento nacional a partir da crítica da Economia Política da CEPAL à luz do 
pensamento marxista e keynesiano e em diálogo crítico com a realidade latino-americana no contexto da crise da dívida na década de 1980.

Para demonstrar o que se pode chamar de evolução da consciência desenvolvimentista, primeiro, serão apresentadas as semelhanças e diferenças com relação à noção de sistema capitalista, aos determinantes da relação centro-periferia e quanto às possibilidades de superação do subdesenvolvimento, tanto no quadro analítico da CEPAL como na Escola de Campinas. Em seguida, serão confrontados os dois esquemas analíticos com o intuito de colocar em relevo a historicidade e complexificação da problemática da superação do subdesenvolvimento. Mais precisamente, será sugerido que a percepção dos obstáculos à superação do subdesenvolvimento está determinada, em primeira instância, pelo momento em que o sujeito do processo do conhecimento forja sua visão de capitalismo em um diálogo crítico com sua matriz teórica fundamental e a realidade concreta em transformação, e, em última instância, pela etapa do capitalismo propriamente dita.

\section{A PERSPECTIVA CEPALINA}

A Comissão Econômica para a América Latina (CEPAL), criada em 1948 com o objetivo de promover o desenvolvimento econômico na região, tem sua origem no contexto de consolidação da hegemonia estadunidense que, na luta contra a União Soviética, fomentou missões e programas de cooperação técnica com os diferentes governos do mundo para difundir o conhecimento técnico necessário ao planejamento e à coordenação conjunta das atividades econômicas em nível mundial. Três textos marcam a contribuição inicial da CEPAL à problemática do desenvolvimento: "O desenvolvimento econômico da América Latina e alguns de seus principais problemas" (1949); "Crescimento, desequilíbrio e disparidades: interpretação do processo de desenvolvimento econômico" (1950); e "Problemas teóricos e práticos do crescimento econômico (1951). Como observa Ricardo Bielschowsky (2011, p. 8), “essa é a trilogia que funda a teoria estruturalista sobre o subdesenvolvimento latino-americano".

$\mathrm{Na}$ leitura de Octavio Rodríguez, está presente nos escritos iniciais da CEPAL, a concepção de desenvolvimento econômico segundo a qual o aumento da renda per capita está associado ao aumento da produtividade média do trabalho em que o incremento da renda corresponde ao aumento do bem-estar material. Uma concepção, portanto, que vincula 
acumulação de capital ao progresso técnico. Diferentemente da Teoria da Modernização, a perspectiva cepalina não considera esta relação dentro de um modelo atomista de economia nacional. Ao contrário, toma como ponto de partida os efeitos de propagação do progresso técnico no interior de um sistema econômico mundial constituído por centros e periferias. (RODRÍGUEZ, 1980, p. 25)

Tal distinção informa o caráter desigual e originário da economia mundial capitalista. O centro está conformado por aquelas economias nas quais a técnica capitalista de produção emerge e se difunde. A periferia, definida em oposição ao centro, envolve todas aquelas economias que permanecem em um estado tecnológico e organizativo defasado em relação ao centro. Cabe salientar que esta distinção não é estabelecida a priori, resulta do processo histórico de difusão do progresso técnico e de como este vai transformando as estruturas produtivas arcaicas. Enquanto no centro os benefícios da introdução de uma nova técnica se generalizam rapidamente para todos os setores, nas economias periféricas tais benefícios ficam circunscritos a setores específicos, em geral ao setor exportador de matériasprimas e aos demais vinculados a este. Visto a partir da estrutura produtiva, as economias centrais e periféricas se particularizam pelo fato de a primeira conformar uma estrutura produtiva diversificada e homogênea, enquanto a segunda, por ser especializada e heterogênea. (RODRÍGUEZ, 1980, p. 25-27)

Dado os ritmos distintos de absorção do progresso técnico, a propagação do mesmo tende a ampliar, no longo prazo, a brecha entre os polos desenvolvidos (centro) e subdesenvolvidos (periferia). Tende a provocar um crescimento desproporcional da produtividade do trabalho e da renda média. No esquema cepalino, tal desproporcionalidade deriva do fato de o progresso técnico ser mais intenso no centro do que na periferia. Precisamente, esta dinâmica desigual é explicada por duas hipóteses: (i) o acréscimo da produtividade do trabalho ser maior no setor industrial do centro do que o acréscimo da produtividade do trabalho no setor exportador da periferia; e, por conseguinte, (ii) pela taxa de crescimento da renda média no centro ser maior do que a taxa de crescimento da renda média na periferia. Ambas as hipóteses se articulam, de acordo com Rodríguez, pela deterioração dos termos de troca, a qual afirma que o "[...] poder de compra de bens industriais de uma unidade de bem primário de exportação se reduz com o passar do tempo." (RODRÍGUEZ, 1980, p. 28). A deterioração dos termos de intercambio é explicada, por sua vez, pela relação que se estabelece entre a estrutura produtiva dos países centrais e a estrutura produtiva dos países periféricos. 
Teoricamente, o primeiro movimento define as seguintes relações básicas. Dada uma determinada estrutura setorial da produção e do emprego, a introdução do progresso técnico tende a incrementar o produto por homem ocupado, elevando, deste modo, a produtividade e a renda média do trabalho. A elevação da renda tende, por sua vez, a expandir e diversificar a demanda agregada. Se se admitir que o progresso técnico é incorporado aos setores secundário e terciário, e que ambos crescem relativamente mais rapidamente que o setor primário, a estrutura de emprego é modificada em função da transformação na estrutura produtiva. (RODRÍGUEZ, 1980, p. 27-28)

O segundo movimento teórico, por sua vez, introduz e articula as relações básicas anteriormente definidas à concepção centro-periferia. Para tanto, admitem-se três hipóteses: (i) a existência de uma economia mundial, na qual a composição setorial da produção e do emprego de cada país se integra pela divisão internacional do trabalho; (ii) que há restrição à mobilidade da força de trabalho; e, por fim, (iii) que existe excesso de mão-de-obra no setor primário das economias periféricas. Assim sendo, dinamicamente, a transformação da estrutura produtiva periférica por meio da introdução do progresso técnico tenderia a absorver o excedente de mão-de-obra do setor primário. Entretanto, uma vez que a oferta da mão-deobra é superior à demanda criada pelo progresso técnico, engendra-se uma tendência constante à queda de renda do trabalho do setor primário-exportador na periferia e, consequentemente, uma redução dos preços de exportação. No centro, ocorre o movimento contrário. Dada a escassez relativa de mão de obra, bem como o nível de organização sindical dos trabalhadores, forma-se a tendência à elevação dos salários. Além disto, do ponto de vista das empresas, há capacidade de preservar as taxas de lucro. Ambas as tendência contribuem para uma elevação dos preços dos produtos manufaturados. Desse modo, quando observado empiricamente os ciclos das relações dos termos de troca, o somatório das perdas acumuladas pela periferia é superior ao somatório dos ganhos acumulados, daí a tendência declinante dos termos de intercambio no longo prazo. (RODRÍGUEZ, 1980, p. 27-31)

$\mathrm{Na}$ concepção centro-periferia da CEPAL, a deterioração dos termos de intercambio sugere, portanto, que os frutos do progresso técnico se concentram nos países industrializados, i.e., no centro. Mais que isto, sugere também que a periferia transfere para o centro parte de seus próprios frutos. (RODRÍGUEZ, 1980, p. 29)

Sendo assim, no esquema cepalino a condição periférica e central está determinada pela estrutura produtiva de cada país que, por sua vez, resulta de um lado pela introdução do 
progresso técnico e, de outro, pela maneira como tal estrutura reage face à tendência declinante dos termos de intercâmbio.

Decorre dessa visão peculiar da economia mundial que a superação do subdesenvolvimento viria pela industrialização. Este argumento se apoiava na constatação empírica de que os níveis de produtividade e de renda média atingidos na América Latina nas primeiras décadas do século XX havia impulsionado o crescimento industrial na periferia. Os constrangimentos impostos pelas duas grandes guerras, bem como pela Crise de 1929, impuseram barreiras à importação, por um lado, e estimularam a expansão da demanda por exportação, por outro. Como consequência de tais restrições, as necessidades internas criaram uma situação favorável ao crescimento da atividade industrial na região. Com isso, o padrão de crescimento hacia afuera foi substituído pelo padrão de crescimento hacia adentro, em que a indústria passava a substituir as exportações como fator dinâmico. (RODRÍGUEZ, 1980, p. 33-35)

Neste momento, as contradições do processo de industrialização na periferia redefiniam a desigualdade centro-periferia. Em primeiro lugar, a tendência ao desequilíbrio externo se aprofunda devido à intensidade da demanda de importações pela periferia e o crescimento inferior da demanda de exportações dos bens primários para o centro. Em segundo lugar, permanece também a tendência ao desemprego estrutural explicado pela situação de abundância de mão-de-obra, que é reforçada pela adoção de técnicas intensivas em capital. Por fim, em terceiro lugar, a adoção de técnicas produtoras em grande escala, cujo volume de capital é alto, esbarra em dois problemas: no baixo nível da renda, que implica na subutilização das plantas industriais devido à insuficiência dos mercados; e na baixa capacidade de poupança, que restringe o investimento simultâneo em diferentes setores e, portanto, implica em uma estrutura produtiva com diferentes níveis de produtividade. Embora todos estes problemas se relacionem com a técnica, que pouco a pouco é incorporada, todas essas contradições se vinculam com a questão da concentração da propriedade da terra. A plena utilização da terra fica comprometida com a grande propriedade por causa do volume de recurso necessário ao seu cultivo. Além disso, no latifúndio predomina a tendência à mecanização da agricultura, que também contribui para elevar o excedente de mão-de-obra. (RODRÍGUEZ, 1980, p. 36-39)

Enfim, o processo de industrialização ocorre sobre uma estrutura produtiva especializada e heterogênea gestada no período hacia afuera. Isto imprime um caráter 
singular ao processo de industrialização na periferia, pois à medida que a estrutura produtiva se diversifica com elevação da produtividade, não se estabelece a complementariedade entre todos os ramos de atividade. Forma-se, assim, uma estrutura desconexa que tampouco é capaz de absorver o desemprego estrutural.

A problemática do desenvolvimento nacional como superação do subdesenvolvimento se coloca, assim, com a tarefa de levar adiante o processo de industrialização através da substituição de importações por meio do planejamento estatal, no qual os problemas estruturais das economias periféricas fossem organizados e racionalizados, de modo que o crescimento acelerado e sustentado pudesse conduzir à redução da brecha entre os países do centro e da periferia.

\section{A PERSPECTIVA DA ESCOLA DE CAMPINAS}

Se nos idos da década de 1950 a superação do subdesenvolvimento viria da superação do atraso tecnológico através da industrialização substitutiva de importações planejada pelo Estado e da esperada distribuição mais equitativa da renda, em meados da década de 1970, Celso Furtado admitiu que a ideia de desenvolvimento econômico era um mito. Como destacou Furtado (1974, p. 75-76), "graças a ela tem sido possível desviar as atenções da tarefa básica de identificação das necessidades fundamentais da coletividade e das possibilidades que abre ao homem o avanço da ciência".

$\mathrm{Na}$ revisão crítica da formação e desenvolvimento da economia brasileira, João Manuel Cardoso de Mello ([1975] 1984, p. 122) expõe, com certo tom de cinismo, que "a industrialização chegara ao fim e a autodeterminação do capital estava, doravante, assegurada. Pouco importava que não tivesse se mostrado capaz de realizar as promessas que, miticamente, lhe haviam atribuído." A Escola de Campinas tem, portanto, sua origem no contexto das frustações engendradas pelo Golpe Militar de 1964, o qual assegurou a manutenção do processo de modernização do Brasil pela via conservadora e excludente.

Não obstante, para se levar adiante a crítica do desenvolvimento capitalista na América Latina, em particular no Brasil, a problemática da "industrialização nacional a partir da situação periférica" foi redefinida criticamente em termos da problemática "da industrialização retardatária”. (MELLO, 1984; TAVARES, 1998a) A crítica da Economia Política da CEPAL esteve inspirada no estudo sistemático da obra de Karl Marx em diálogo 
com os grandes pensadores contemporâneos como Schumpeter, Keynes e Kalecki, bem como Hilferding e Steindl. (Cf. MELLO, 1999) Nos escritos mais recentes, deve-se ressaltar ainda a contribuição de Minsky. Como resultado, conformou-se uma Economia Política própria, segundo a qual "a História brasileira e latino-americana é História do capitalismo" e "[...] a História do capitalismo é também a nossa história". (MELLO, 1984, p. 176-177) Rigorosamente,

a industrialização capitalista, portanto, deve ser entendida como o processo de constituição de forças produtivas capitalistas, mais precisamente como o processo de passagem ao modo especificamente capitalista de produção, ao que é impropriamente chamado de capitalismo industrial. (MELLO, 1984, p. 97)

Sem assim, a visão de sistema capitalista forjada pela Escola de Campinas tem como ponto de partida a interpretação da teoria do valor de Marx, a qual compreende como sendo uma teoria da valorização do valor. (Cf. BELLUZZO, 1980) A preocupação central da incorporação das categorias marxistas está nas formas de concretização da lei do valor. Desse modo, estuda-se a dinâmica contraditória das formas capitalistas (mercantil, produtivo e financeiro) através do tempo e do espaço, e a correspondente estrutura capitalista que emana desta dinâmica tanto na etapa concorrencial quanto na etapa monopolista. Portanto, o objetivo é apreender a singularidade dos diferentes capitalismos que constituem o sistema mundial capitalista a partir da historicização da lei valor e pela definição de modelos endógenos de acumulação. Ou, dito de outro modo, pela capacidade de diversificação da estrutura produtiva a partir da introdução do progresso técnico. (Cf. TAVARES, 1998a)

Teoricamente, os diferentes capitalismos estão determinados, em primeira instância, pela formação econômico-social precedente ao capitalismo e, em última instância, pelo marco do capitalismo nacional mais avançado. Historicamente, identificam três padrões de formação capitalista, denominados originário, avançado e tardio. $\mathrm{O}$ capitalismo originário sintetiza e descreve o padrão de formação do capitalismo inglês. Este esteve vinculado ao processo de acumulação primitiva. Foi o capitalismo, cuja origem esteve apoiada na violência extraeconômica do Estado, no sistema colonial, de dívida pública, tributário e protecionista. $\mathrm{O}$ capitalismo atrasado, por sua vez, divide-se em dois grupos: no primeiro, o processo de industrialização ocorreu no momento em que o capitalismo inglês era dominante no mercado mundial (etapa concorrencial); no segundo grupo, a industrialização se dá na crise etapa concorrencial, ou seja, na transição à etapa monopólica, momento em que se aprofundavam as condições técnicas e financeiras à industrialização. Por fim, o capitalismo tardio é o padrão de 
formação do capitalismo cujo processo de industrialização tem origem em sociedades de passado colonial na etapa monopolista do capitalismo. (MELLO, 1984; OLIVEIRA, 2003)

Cada padrão de formação capitalista implica, consequentemente, em padrões endógenos distintos de acumulação, isto é, problemas específicos de realização do valor no movimento de valorização progressiva do capital. Noutras palavras, cada padrão apresenta uma dinâmica capitalista particular que favorece ou impõem obstáculos à autodeterminação do capital. (BRAGA, 1985; MAZZUCCHELLI, 1985; TAVARES, 1998a, 1998b)

Quando se "abre" o esquema inicial da Escola de Campinas em direção à interpretação do sistema capitalista, o sistema centro-periferia correspondente a esta perspectiva não está determinado exclusivamente pelo progresso técnico e pela divisão internacional do trabalho. A crítica da Economia Política da CEPAL explora o caráter desigual do sistema capitalista a partir do padrão monetário internacional. Esta "correção de rota" dos mestres cepalinos deriva da constatação, já mencionada, da não superação do subdesenvolvimento através da industrialização, que levou os artífices da Escola de Campinas a refletirem, a partir de meados da década de 1970, sobre o caráter da industrialização periférica.

Analiticamente, parte-se da existência de um sistema mundial capitalista, cuja origem remonta à Europa do século XVI e que se organiza a partir da relação conflituosa entre capital e Estado. Enquanto a concorrência entre as diferentes formas de capital em busca de valorização dá origem a padrões de concorrência, que estão associados ao tipo dominante de empresa capitalista em cada período da História do capitalismo; a concorrência entre os Estados nacionais, por sua vez, dá origem a um sistema interestatal capitalista que, em cada momento do tempo, organiza-se a partir de um poder hegemônico, o qual define não apenas a via de acumulação de poder político, mas também institucionaliza os mecanismos de regulação da forma dominante da acumulação capitalista (hegemonia inglesa e estadunidense, por exemplo). (TAVARES; BELLUZZO, 2005)

A articulação entre o poder econômico e o poder político tem expressão concreta, para a Escola de Campinas, nos regimes monetários internacionais (padrão-ouro clássico, gold exchange standard, padrão ouro-dólar e padrão dólar-flexível). Cada regime monetário internacional pressupõe diferentes formas de estruturação dos sistemas financeiros nacionais (sistema de pagamentos e administração da liquidez), ao mesmo tempo em que implica em formas distintas de articulação entre os mesmos. Sucede que ciclos de liquidez internacional adquirem configuração própria em função do regime monetário internacional. A opção pelo 
regime monetário internacional como eixo estruturante da análise se justifica teoricamente à medida que o capital financeiro torna-se dominante e se aprofunda na etapa monopolista do capitalismo. Portanto, as formas de dominação do centro sobre a periferia se exprimem na forma de estruturação do regime monetário internacional na medida em que, dada a profundidade tecnológica e financeira, a condição de acesso à liquidez internacional impõe contrapartidas que ora dão vazão e ora constrangem a política monetária e fiscal dos Estados periféricos. (BELLUZZO, 2009; CARNEIRO, 2007, 2010; TAVARES; BELLUZZO, 2005)

Sendo assim, as diferentes etapas do capitalismo podem ser apreendidas, à luz da Escola de Campinas, a partir da evolução dos regimes monetários internacionais. Se a crise do gold exchange standard representou o encerramento da etapa concorrencial do capitalismo, o Sistema de Bretton Woods simbolizou a consolidação da etapa monopolista, não obstante a peculiar capacidade de controlar as finanças através das restrições à mobilidade de capitais e da adoção do sistema de câmbio fixo. Ocorre que a crise do regime de Bretton Woods marcou, por seu turno, uma nova fase do capitalismo monopolista em que o capital financeiro se libertou das amarras dos Estados e passou a comandar novamente os ciclos.

Do ponto de vista da problemática do desenvolvimento nacional interessa a comparação entre a finança regulada e sua posterior desregulação. Foi no regime de Bretton Woods que a problemática da superação do subdesenvolvimento através da industrialização, tal como proposta pela CEPAL, adquiriu força política. Enquanto fundamento da ordem internacional que marcou o pós-Segunda Guerra Mundial, o regime de Bretton Woods foi organizado para estimular o comércio mundial e assegurar a liquidez necessária à expansão sem a necessidade de ajustes deflacionários do balanço de pagamentos. Como bem observou Belluzzo (2009, p. 75), “tratava-se, portanto, de erigir um ambiente econômico internacional destinado a propiciar um amplo raio de manobra para as políticas nacionais de desenvolvimento".

Neste período, a finança estava apoiada em um sistema de crédito bancário em que: a política monetária e de crédito tinha caráter nacionalista; os sistemas financeiros nacionais se organizavam a partir das normas de operação que determinavam as regras de operação das instituições financeiras de acordo com o segmento de mercado, bem como estabelecia os limites de operação de crédito; além disso, os Bancos Centrais dispunham de maior flexibilidade para assegurar a liquidez necessária aos bancos privados. O regime de Bretton Woods tinha, portanto, o compromisso com o crescimento econômico e com a elevação do emprego e dos salários reais. O resultado foi a conformação de uma "economia do 
endividamento", na qual a intensificação da concorrência intercapitalista e o conflito distributivo entre capitalistas e trabalhadores engendraram a crise da finança regulada. (BELLUZZO, 2009, p. 76)

$\mathrm{Na}$ perspectiva da "Escola de Campinas", o sistema monetário internacional se estrutura hierarquicamente a partir de uma moeda reserva e se dinamiza a partir das inovações financeiras, cujo objetivo é minimizar o risco da volatilidade dos preços dos ativos, bem como o de contornar as restrições à liquidez impostas pelos mecanismos de regulação. (Cf. CARNEIRO, 2010). Dada a elevação do patamar da inflação e a queda da taxa de lucro decorrente da intensificação da concorrência intercapitalista a partir de meados da década de 1960, a criação do euromercado, do mercado offshore, de instrumentos como hedge e de negociação de títulos de dívida públicos e privados foram inovações financeiras que prenunciaram a crise do regime de Bretton Woods, dando início ao processo de liberalização no qual as finanças redefiniram o modo de funcionamento do sistema capitalista mundial. (BELLUZZO, 2009, p. 78-81)

Apesar do desmoronamento de Bretton Woods, o dólar preservou sua posição de moeda reserva no sistema monetário internacional. Teoricamente, de acordo com a Escola de Campinas, são dois os requisitos para que determinada moeda desempenhe o papel de moeda reserva: sua conversibilidade, isto é, “[...] a capacidade de ancorar a riqueza em ativos com liquidez e reconvertê-los na moeda de origem sem perdas de capital" (CARNEIRO, 2010, p. 2); e o grau em que as transações públicas e privadas estão denominadas nesta determinada moeda. (CARNEIRO, 2010, p. 1-4) A despeito do fim da paridade dólar-ouro, os contratos comerciais e financeiros internacionais continuaram designados em dólar, bem com as reservas internacionais, sob controle dos bancos centrais, igualmente seguiram especificadas em dólar. Isto preservou a posição central dos Estados Unidos, o que lhes deu autonomia para definir unilateralmente a taxa de juros.

Com a desregulamentação das finanças no capitalismo contemporâneo, a contradição entre o caráter público e privado da moeda no exercício da função de reserva de valor caracteriza a dinâmica de funcionamento do sistema monetário internacional, por um lado, e redefine a conduta das empresas financeiras e não financeiras, e das famílias, por outro.

Como no regime do capital sob dominância financeira, a conduta dos agentes privados é orientada para a maximização do ganho patrimonial, a estratégia de governança das empresas não financeiras se reorientou à sua sobrevalorização acionária. Isto implicou numa tendência à especialização das empresas em atividades do núcleo estratégico, em sua 
maioria tarefas de alta densidade tecnológica e de maior rentabilidade. Consequentemente, difundiram-se as redes de subcontratação, criando uma hierarquia de lucros inter-empresas. Em termos de organização da produção, isto acarretou na desverticalização da empresa transnacional típica do período Bretton Woods. As formas de financiamento do investimento também foram redefinidas, expandindo as captações via mercado de capitais em detrimento do crédito bancário. Sendo assim, mesmo as empresas não financeiras passaram a orientar a gestão patrimonial em direção à posições mais líquidas. No que tange às empresas financeiras, bancos e investidores institucionais se tornam personagens centrais no processo de valorização do capital na era da globalização, pois concentram elevadas massas de riqueza, bem como controlam o acesso ao crédito, que permite o processo de concentração e centralização do capital em escala global. No caso das famílias, o consumo passou a depender muito mais do crédito do que da renda corrente. Desse modo, as famílias têm decidido sobre seus gastos comparando a taxa de crescimento de suas dívidas com a taxa de valorização da renda financeira. (CARNEIRO, 2007, p. 13-17)

Fica claro, desde logo, que o modo operandi do capitalismo contemporâneo difere significativamente daquele no qual as teses originárias da CEPAL foram escritas. O tipo de integração mundial promovido pelo IED na primeira metade do século XX se transfigurou com a crise do sistema de Bretton Woods. A nova divisão internacional do trabalho, na era da microeletrônica e organizada a partir da empresa em rede fundada numa lógica financeirizada, redefine o caráter da relação centro-periferia.

Do ponto de vista da relação centro-periferia, conforme sugerem Tavares \& Belluzzo (2005, p. 124), diferentemente da Inglaterra, a expansão "para fora" do capitalismo estadunidense “[...] não se dá apenas nem fundamentalmente pelo comércio, mas, sobretudo pelas filias do grande capital financeiro trustificado". E concluem: com a emergência de uma periferia produtora de artigos manufaturados baratos e importadora de matérias-primas (Ásia) se:

[...] alteram completamente os termos da relação Centro-Periferia proposta pela Inglaterra e teorizada por Raúl Prebisch... As relações de troca no comércio mundial deixam de inclinar-se a favor das manufaturas e contra os Produtos Primários porque é no território dos países asiáticos de mão de obra barata e com abundância de IDE que se produzem as novas manufaturas. (TAVARES \& BELLUZZO, 2005, p. 124)

Assim sendo, os determinantes da relação centro-periferia são revisitados no interior da estrutura conceitual da "Escola de Campinas". Dada a dominância do capital financeiro, a dimensão produtiva está subordinada à estratégia de valorização patrimonial da riqueza capitalista, o que torna mais complexa a definição de centro e periferia. 
De acordo com João Manuel Cardoso de Mello (1997, p. 16),

[...] se poderia definir o Centro capitalista por três tipos de controles: o primeiro deles se exerceria sobre o processo de inovação tecnológica, o que supõe formas de organização capitalista nas quais estaria encarnado o poder financeiro; o segundo concerne à moeda e à finança internacionalizada, o que por sua vez pressupõe o poder industrial; o terceiro diz respeito ao poder político-militar, em última instância, o controle das armas.

Por oposição, e como resultado da expansão do centro capitalista, a periferia subdesenvolvida caracteriza-se: por seu sistema produtivo ser dependente dinamicamente; pelo caráter frágil de sua moeda e de suas finanças externas; e por sua posição político-militar subordinada no sistema interestatal. (MELLO, 1997, p. 18)

A partir dessa noção de periferia, é possível distinguir duas modalidades de integração: aquelas que se articulam produtivamente e aquelas que se articulam financeiramente. (BELLUZZO, 2006, p. 41) Ricardo Carneiro avança matizando esta sugestão. De acordo com este autor, o tipo de integração periférica varia de acordo com a intensidade, maneira e o grau do vínculo produtivo ou financeiro que um determinado país ou região estabelece com o processo global de valorização do capital. Em termos gerais, dada a etapa do capitalismo e o regime monetário internacional, a integração da periferia pode ser matizada a partir da análise: do fluxo de capitais (bruto versus líquido); da estratégia de formação dos portfólios; do grau de liquidez dos ativos; do direcionamento do fluxo de capitais (unidirecional versus multidirecional); da concentração espacial do fluxos de capitais (centro-centro versus centro-periferia); do perfil do investimento estrangeiro (carteira versus direto); o prazo do investimento (curto ou longo); do regime cambial (fixo ou flutuante); e da estratégia do IED (resource seeking, market seeking, efficiency seeking e strategic-asset seeking). (CARNEIRO, 2007, p. 18-23)

Carneiro (2007) também analisa o desempenho do tipo de integração periférica e estreitamento da brecha em relação aos países desenvolvidos, i.e., a convergência e divergência em termos de renda per capita e gap-tecnológico. As evidencias têm sugerido que a integração produtiva tende a contribuir para a redução da distância entre países subdesenvolvidos e desenvolvidos ao passo que a integração financeirizada, ao contrário, tende a ampliar a desigualdade.

Em suma, para se pensar o sistema capitalista, os determinantes da relação centroperiferia e as condições para a superação do subdesenvolvimento são essenciais para a Escola de Campinas considerar as transfigurações da riqueza e suas implicações sobre a lógica de funcionamento do modo capitalista de produção, das formas de organização e articulação dos diferentes capitalismos nacionais em cada etapa da História do capitalismo. É neste sentido 
que a "Escola de Campinas" avança na direção de se libertar do certo formalismo do qual a CEPAL fora refém (ver quadro 1).

Do ponto de vista dos determinantes da relação centro-periferia, à luz da Escola de Campinas, a consolidação da indústria na periferia revelou a historicidade da hipótese da difusão do progresso técnico como móvel da desigualdade centro-periferia. A tendência à deterioração dos termos de intercâmbio também não se verificou indefinidamente declinante. O comportamento cíclico dos preços das commodities imprime tendência altista e baixista aos termos de intercâmbio. Isto não significa, conforme tem sugerido Carneiro (2012, p. 44), que, na alta, a exportação de commodities consista em uma solução de longo prazo.

Procede, segundo a Economia Política da Escola de Campinas, que a superação do subdesenvolvimento requer: sobrepujar a dependência dinâmica do setor produtivo; fortalecer a moeda e extenuar a fragilidade financeira externa; e fortalecer a posição político-militar no sistema interestatal. Logo, a industrialização per si não foi, e tampouco será, a estratégia mais adequada para a superação do subdesenvolvimento. Esta cumpre um papel essencial, porém seu valor estratégico está determinado pela etapa do capitalismo e pelo regime monetário internacional, os quais definem as estratégias dominantes de valorização da riqueza. A dificuldade política reside em subordinar o processo de valorização da riqueza ao interesse da sociedade. Decorre daí a importância do papel do Estado e, sobretudo, de um projeto nacional de desenvolvimento.

Quadro 1 - Síntese do pensamento originário da CEPAL comparado à Escola de Campinas.

\begin{tabular}{|l|l|l|}
\hline & Pensamento Originário da CEPAL & \multicolumn{1}{c|}{ Escola de Campinas } \\
\hline $\begin{array}{l}\text { Noção de sistema } \\
\text { capitalista }\end{array}$ & $\begin{array}{l}\text { Divisão internacional do trabalho } \\
\text { estruturada de modo axiforme entre um } \\
\text { centro e uma periferia. }\end{array}$ & $\begin{array}{l}\text { Divisão internacional do trabalho } \\
\text { envolvida e fragmentada por um } \\
\text { sistema interestatal estruturada com } \\
\text { base em um centro e uma periferia. }\end{array}$ \\
\hline $\begin{array}{l}\text { Determinantes da } \\
\text { relação centro- } \\
\text { periferia }\end{array}$ & $\begin{array}{l}\text { Propagação desigual do progresso } \\
\text { técnico. }\end{array}$ & $\begin{array}{l}\text { Além da propagação desigual do } \\
\text { progresso técnico, leva em } \\
\text { consideração os regimes monetários } \\
\text { internacionais e a capacidade dos } \\
\text { Estados concentrarem os meios de } \\
\text { coerção. }\end{array}$ \\
\hline $\begin{array}{l}\text { Estratégia para } \\
\text { superação do } \\
\text { subdesenvolvimento }\end{array}$ & Industrialização planejada pelo Estado. & $\begin{array}{l}\text { A industrialização planejada pelo } \\
\text { Estado per si não é suficiente para: } \\
\text { superar a dependência dinâmica do } \\
\text { setor produtivo; fortalecer a moeda e } \\
\text { extenuar a fragilidade externa dela } \\
\text { decorrente; e para fortalecer o poder } \\
\text { político-militar no sistema interestatal. }\end{array}$ \\
\hline
\end{tabular}

Fonte: Elaboração do autor. 


\section{CONSIDERAÇÕES FINAIS}

$\mathrm{O}$ que possui de fundamentalmente diferente a Escola de Campinas em relação ao pensamento originário da CEPAL? As diferenças se explicitam mais na fundamentação teórica da teoria do subdesenvolvimento do que em seu valor normativo.

Contrapondo os dois sistemas de economia política, no que tange à noção de sistema capitalista, aos determinantes da relação centro-periferia e às estratégias para a superação do subdesenvolvimento, pode-se afirmar que tanto a CEPAL quanto a Escola de Campinas compartilham da visão segundo a qual a problemática do desenvolvimento nacional é o da superação do subdesenvolvimento. Ambas as escolas também destacam a centralidade do Estado como agente do processo de superação do subdesenvolvimento.

Não obstante, a supressão dos regimes de governo democráticos a partir da década de 1960 e o desencantamento com a industrialização na década de 1970 impuseram à razão desenvolvimentista a necessidade de revisitar seus fundamentos teóricos. Neste contexto, a tese do Capitalismo Tardio lançou as bases para a crítica interna do desenvolvimentismo.

Visto em perspectiva, o sistema capitalista deixou de ser considerado exclusivamente como um sistema econômico mundial fundado em uma divisão internacional do trabalho estruturada de modo axiforme entre um centro e uma periferia. A Escola de Campinas trouxe para dentro da teoria do subdesenvolvimento as determinações políticas do sistema interestatal que tornam mais complexas as relações entre países centrais e periféricos.

Sendo assim, a posição dos países no sistema mundial deixou de ser explicada pela posição que cada país ocupava na divisão internacional do trabalho em função da propagação desigual do progresso técnico. Para compreender as hierarquias mundiais, em especial, a dinâmica da relação centro-periferia, a Escola de Campinas complementou o esquema cepalino ao introduzir na análise os regimes monetários internacionais bem como a capacidade de concentração dos meios de coerção pelos Estados. Consequentemente, a constatação destas complexidades tornaram mais perniciosa as condições de superação do subdesenvolvimento. A industrialização per si já não seria mais suficiente para superar a dinâmica dependente da indústria na periferia, ou para criar as bases para uma moeda forte capaz de reduzir a fragilidade externa dos países dependentes. Tampouco industrializar era garantia de inflar o poder político-militar das nações periféricas de modo a competir com os países centrais.

Quando se confronta ambas as perspectivas, observa-se a assimilação e recomposição do pensamento originário da CEPAL pela Escola de Campinas em um nível 
maior de complexidade. Tal démarche teórica expressa, na verdade, a incorporação à teoria do subdesenvolvimento das transformações na realidade latino-americana engendradas pela transfiguração do capital a partir do desmoronamento de Bretton Woods.

Portanto, a Escola de Campinas parece não abandonar o campo político cepalino de superação do subdesenvolvimento através das reformas estruturais em bases democráticas. $\mathrm{Na}$ verdade, ela propôs uma revisão crítica dos fundamentos teóricos do estruturalismo latinoamericano de modo a fundamentar e instrumentalizar a luta política pela redemocratização com vistas à inserção nacional soberana no sistema mundial capitalista financeirizado. (Cf. SANTOS, 2012, capítulo 3, seção 4.)

Se tal leitura não está equivocada, pode-se sugerir que a Escola de Campinas representa, em certo sentido, a evolução de certa consciência desenvolvimentista.

\section{REFERÊNCIAS BIBLIOGRÁFICAS}

BELLUZZO, L. G. DE M. Valor e capitalismo: um ensaio sobre a economia politica. São Paulo, SP: Brasiliense, 1980.

BELLUZZO, L. G. DE M. As transformações da economia capitalista no pós-guerra e a origem dos desquilíbrios globais. In: A supremacia dos mercados e a política econômica do governo Lula. São Paulo, SP: Ed. UNESP, 2006.

BELLUZZO, L. G. DE M. O dinheiro e as metamorfoses da riqueza. In: Os antecedentes da tormenta: origens da crise global. Campinas, SP: Facamp, 2009.

BIELSCHOWSKY, R. Prefácio: Prebisch e Furtado. In: PREBISCH, R.; AL., E. (Eds.). $O$ manifesto latino-americano: e outros ensaios. Rio de Janeiro, RJ: Contraponto, 2011. p. 7-14.

BRAGA, J. C. DE S. Temporalidade da riqueza: uma contribuição a teoria da dinâmica capitalista. [s.1.] Universidade Estadual de Campinas, 1985.

CARNEIRO, R. Globalização e Integração Periférica. Campinas, SP: [s.n.].

CARNEIRO, R. O Dólar e seus Rivais.Observatório da Economia Global. Campinas, SP: [s.n.]. Disponível em: $<$ http://www3.eco.unicamp.br/cecon/images/arquivos/observatorio/O_dolar_e_seus_ri vais.pdf $>$.

CARNEIRO, R. Commodities, choques externos e crescimento: reflexões sobre a América Latina. Serie Macroeconomia para el Desarollo, v. 117, 2012.

FURTADO, C. Teoria e Política do Desenvolvimento Econômico. 3. ed. São Paulo, SP: Campanhia Editora Nacional, 1967. 
FURTADO, C. O Mito do Desenvolvimento Econômico. Rio de Janeiro, RJ: Paz e Terra, 1974.

MAZZUCCHELLI, F. A contradição em processo: o capitalismo e suas crises. São Paulo, SP: Brasiliense, 1985.

MELlO, J. M. C. DE. O Capitalismo Tardio: contribuição à revisão crítica da formação e do desenvolvimento da economia brasileira. São Paulo, SP: Brasiliense, 1984.

MELLO, J. M. C. DE. A Contra-revolução liveral-conservadora e a tradição crítica latinoamericana. Um prólogo em homenagem a Celso Furtado. Economia e Sociedade, v. 9, p. 159-164, dez. 1997.

MELLO, J. M. C. DE. Entrevista. In: MANTEGA, G.; RÊGO, J. M. (Eds.). . Conversas com economistas brasileiros II. São Paulo, SP: Editora 34, 1999.

OLIVEIRA, C. A. B. DE. Processo de Industrialização: do capitalismo originário ao atrasado. São Paulo, SP: Ed. UNESP, 2003.

RODRÍGUEZ, O. La teoría del subdesarrollo de la CEPAL. Mexico: Siglo XXI Editores, 1980.

SANTOS, F. P. DOS. Crise e $(m)$ desenvolvimento: a contribuição da escola de Campinas. Campinas, SP: s.n., 2012.

SUNKEL, O.; PAZ, P. El subdesarrollo latinoamericano y la teoría del desarrollo. 6. ed. ed. México: Siglo Veintiuno Editores, 1970.

TAVARES, M. DA C. Acumulação de capital e industrialização no Brasil. 3. ed. Campinas, SP: Unicamp, IE, 1998a.

TAVARES, M. DA C. Ciclo e Crise: o movimento recente da industrialização brasileira. Campinas, SP: Unicamp, IE, 1998b.

TAVARES, M. DA C.; BELLUZZO, L. G. DE M. A mundialização do capital e o poder americano. In: FIORI, J. L. (ORG. . (Ed.). . O Poder Americano. Rio de Janeiro, RJ: Vozes, 2005. 